\title{
A Qualitative Analysis of Malpractice Litigation in Cardiology Using Case Summaries Through a National Legal Database Analysis
}

Richa Patel ${ }^{1}$, Nicole Rynecki ${ }^{1}$, Eric Eidelman ${ }^{2}$, Spandana Maddukuri ${ }^{1}$, Varun Ayyaswami ${ }^{2}$, Manthan Patel $^{3}$, Raghav Gupta ${ }^{1}$, Arpan V. Prabhu ${ }^{4}$, Jared Magnani ${ }^{5}$

1. Medicine, Rutgers University New Jersey Medical School, Newark, USA 2. Medicine, University of Maryland School of Medicine, Baltimore, USA 3. Medicine, Philadelphia College of Osteopathic Medicine, Philadelphia, USA 4. Radiation Oncology, Winthrop P. Rockefeller Cancer Institute, University of Arkansas for Medical Sciences, Little Rock, USA 5. Cardiology, University of Pittsburgh Medical Center Heart and Vascular Institute, Pittsburgh, USA

Corresponding author: Richa Patel, rp612@njms.rutgers.edu

\section{Abstract}

\section{Introduction}

Physicians are increasingly practicing defensive medicine as a response to society's litigious climate. This study sought to characterize cardiology malpractice claims and elucidate the allegations underlying the use of defensive medicine.

\section{Methods}

The WestlawNext ${ }^{\mathrm{TM}}$ database was queried to obtain state and federal jury verdicts and settlements related to medical malpractice and cardiology that occurred in the United States between 2010 and 2015. Cardiology cases were identified using the search terms "medical malpractice" and "cardiology" and reviewed by two individuals utilizing available case documents. Duplicate and nonpertinent cases were excluded. Binary logistic regression models were created to predict the likelihood of defendant verdict, plaintiff verdict, and settlement based on the various reasons for litigation cited.

\section{Results}

Inclusion criteria were met in 166 cases. The plaintiffs were predominantly male (94 cases; 56.6\%), and the average patient age was $53.3 \pm 17.5$ years. More than half of the cases involved a cardiologist as a defendant. The most common reasons for litigation were: failure to treat (129; 77.7\%), failure to diagnose $(115 ; 69.3 \%)$, failure to refer/order diagnostic tests $(107 ; 64.5 \%)$, and patient death $(118 ; 71.1 \%)$. Among cases tried for failure to diagnose, the most commonly missed diagnosis was myocardial infarction. Cases most commonly resulted in a defendant verdict (94; 56.6\%). However, odds of a plaintiff verdict were significantly higher when failure to diagnose was alleged with an odds ratio (OR) of 7.60 (95\% confidence interval 1.14-50.87, p $=0.0365$ ).

Received 05/08/2019

Review began 05/12/2019 Review ended 07/26/2019 Published 07/28/2019

\section{() Copyright 2019}

Patel et al. This is an open access article distributed under the terms of the Creative Commons Attribution License CC-BY 3.0., which permits unrestricted use, distribution, and reproduction in any medium, provided the original author and source are credited.

\section{Conclusions}

Failure to diagnose remains a commonly alleged base for litigation. In conclusion, our analysis suggests increased training for non-cardiologists in the recognition of the acute coronary syndrome and enhanced awareness of inherent biases among all physicians may facilitate reducing missed diagnoses.

Categories: Cardiology

Keywords: medical malpractice, cardiology, legal database analysis

\section{Introduction}

Physicians' principal duty is to provide the highest quality medical care for patients. However, fear of litigation may impact how physicians approach and evaluate potential diagnoses. The use of defensive medicine, or medical practices performed to protect physicians from liability claims, has become the norm in many contemporary medical practices [1-3]. Physicians may order diagnostic imaging or procedures to rule out serious and even unlikely diagnoses to reduce the possibility of litigation [2]. Defensive medicine has been criticized because of its contribution towards increased healthcare costs; it is estimated that the costs of defensive medicine totaled over $\$ 45$ billion dollars in 2008 [4]. US cardiologists are more likely to face malpractice claims than non-cardiologists (8.6\% versus $7.4 \%$ ), and litigation rates for cardiologists are surpassed only by gastroenterologists and cardiothoracic surgeons [5]. Previous characterization of cardiology medical malpractice claims found that diagnostic error was the leading cause for litigation [5, 6].

We queried WestlawNext ${ }^{\mathrm{TM}}$, an online database of legal proceedings, to characterize cardiology malpractice litigation from 2010 to 2015. Our goals were twofold: first, we sought to characterize the reasons for 
litigation of medical malpractice claims against defendant cardiologists; second, we aimed to determine the associations between the cited bases for litigation and defendant or plaintiff verdicts. Previous literature has indicated that the tendency to litigate is largely based on the patient's perception of the doctor-patient relationship [7, 8]. As a result, we hypothesize that despite a climate of increased use of defensive medicine, failure to diagnose remains a common reason for litigation among cardiology cases and is associated with increased odds of plaintiff verdict.

\section{Materials And Methods}

The WestlawNext ${ }^{\mathrm{TM}}$ legal database (Thomson Reuters, New York, NY) was used to characterize cardiology malpractice-related state and federal jury verdict and settlement reports in the United States between January 1, 2010 and December 31, 2015 [9]. The WestlawNext ${ }^{\mathrm{TM}}$ registry is widely used for legal research and incorporates multiple legal databases with an advanced search algorithm [10]. Results include relevant case documents such as jury verdicts, settlements, and case summaries, thereby allowing for review of litigated cases. The database is updated regularly with content supervised by attorney editors responsible for accurately categorizing and summarizing cases, and has had extensive application in analyses of medical malpractice [11-13].

We queried WestlawNext ${ }^{\mathrm{TM}}$ with the search terms "medical malpractice" and "cardiology." Two independent reviewers (Varun Ayyaswami - VA and Eric Eidelman - EE) reviewed the available documents for the 224 cases identified by the search. The reviewers examined 10 cases to ensure consistent categorization followed by each reviewer examining $50 \%$ of the remaining cases. Reviewers identified duplicate cases and those not pertinent to cardiovascular disease during review. The following were extracted from the remaining cases for each verdict or settlement: the state in which the trial was conducted, defendant specialty and membership in hospital group, plaintiff age and sex, reasons for litigation, patient death, jury verdict, and value of monetary award. The reasons for litigation were determined for each case through review of available case files and cases were classified with one or more reasons for litigation as used by previous malpractice studies $[9,11,14]$. Reasons for litigation were characterized by our reviewers as failure to treat, failure to diagnose, failure to refer/order diagnostic tests, procedural error, severe hospitalization, unnecessary surgery, lack of informed consent, and death.

Binary logistic regression models were created to predict likelihood of defendant verdict versus plaintiff verdict, defendant verdict versus case settlement, and plaintiff verdict versus case settlement. Odds ratios (OR) and 95\% confidence intervals (CI) were calculated for patient age greater than 65 years and each reason for litigation. A p-value of $<0.05$ was considered statistically significant. Regressions were performed in SAS Enterprise Guide 7.1 (SAS Institute Inc., Cary, NC, USA).

\section{Results}

Following exclusions for duplicate cases $(n=16)$ or not related to cardiovascular disease $(n=39)$, there were 166 cases available for review, as summarized by Figure 1 . Plaintiffs for the 166 cases were predominantly male ( $\mathrm{n}=94 ; 56.6 \%$ ), and the age of the affected patient was $53.3 \pm 17.5$ years. Table 1 summarizes characteristics of the cases and Table 2 presents reasons for litigation. Cases were distributed amongst 24 US states with the majority being tried in Florida (30; 18.1\%) followed by New York (19; $11.5 \%)$, California, and Massachusetts (both 18; 10.8\%) (Table 3). 


\section{Cureus}

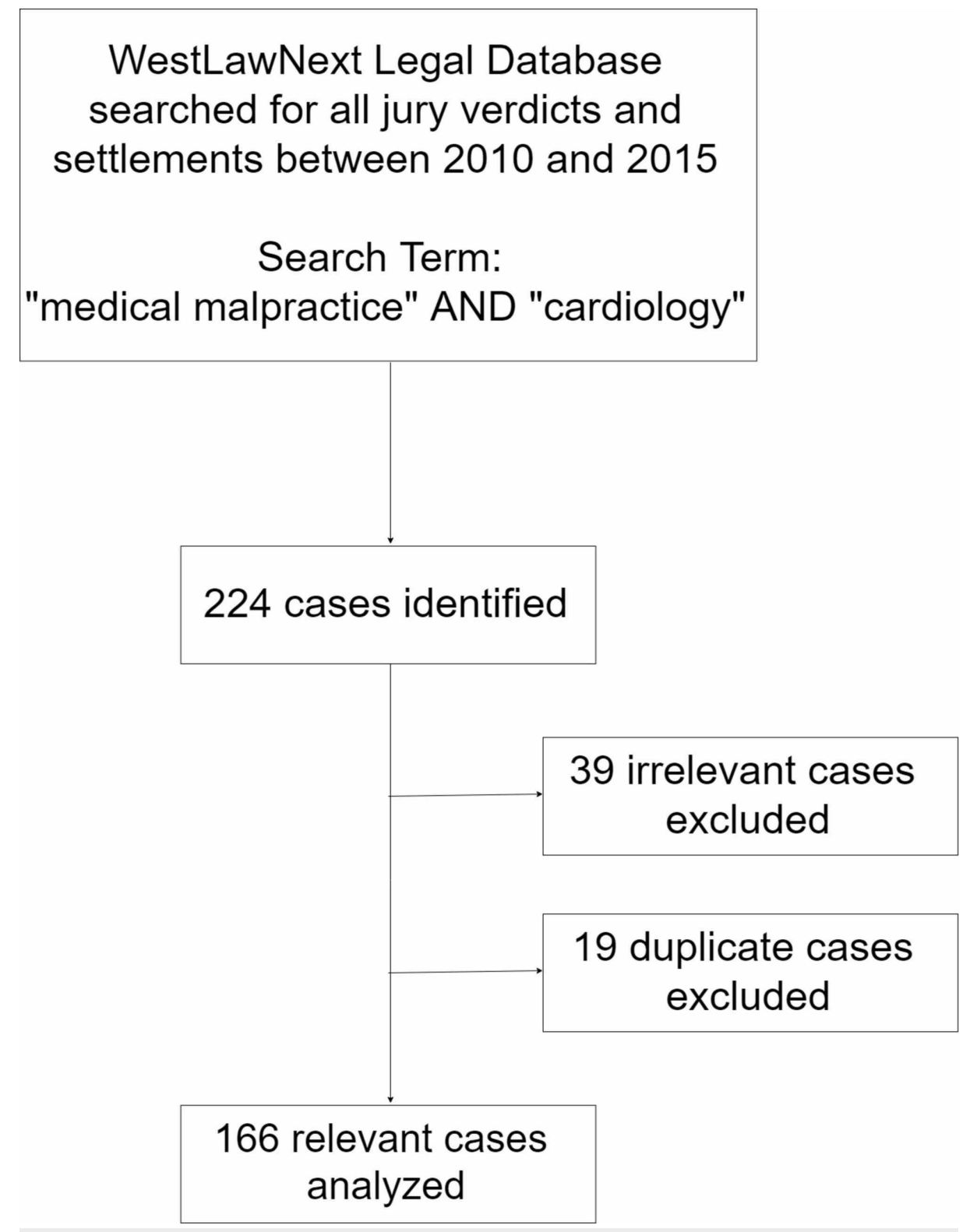

FIGURE 1: Isolation of cases

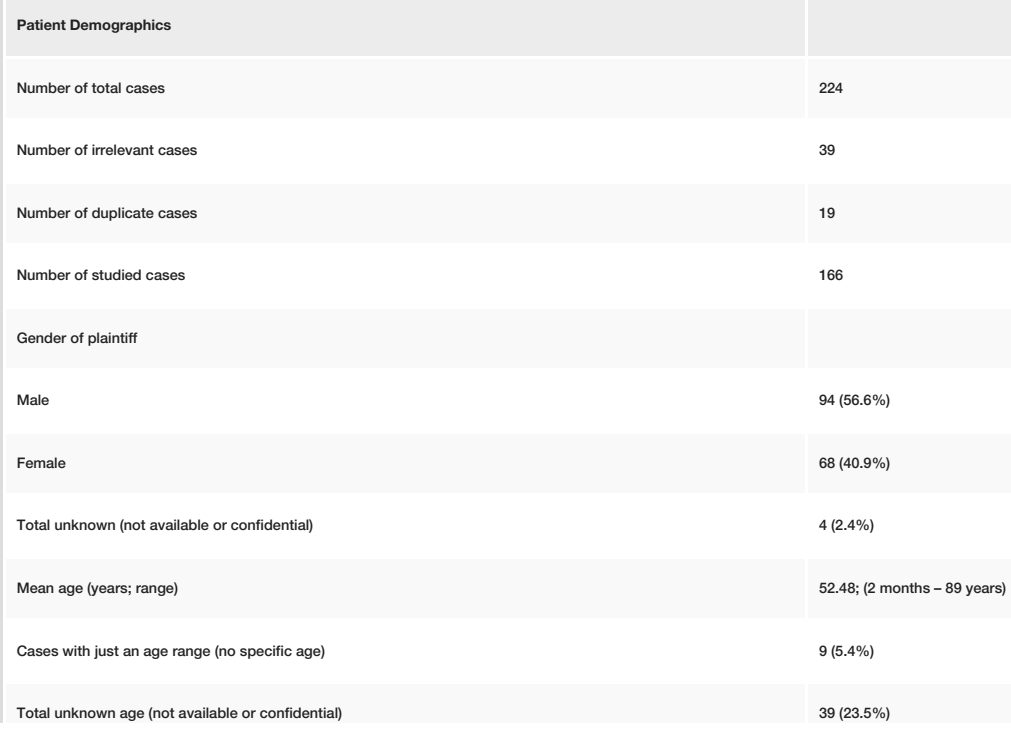




\section{Cureus}

\begin{tabular}{|c|c|}
\hline Number of defendants & \\
\hline 1 & $58(34.9 \%)$ \\
\hline 2 & $51(30.7 \%)$ \\
\hline 3 & $22(13.3 \%)$ \\
\hline 4 & $9(5.4 \%)$ \\
\hline 5 & $7(4.2 \%)$ \\
\hline 6 & $9(5.4 \%)$ \\
\hline 7 & $3(1.8 \%)$ \\
\hline 9 & $3(1.8 \%)$ \\
\hline 10 & $1(0.6 \%)$ \\
\hline Not available or confidential & $3(1.8 \%)$ \\
\hline Cases that involved a cardiologist as a defendant & 109 (65.7\%) \\
\hline Hospital or medical group involvement & \\
\hline Yes & $107(64.9 \%)$ \\
\hline No & $55(33.3 \%)$ \\
\hline Unknown & $3(1.8 \%)$ \\
\hline Year verdict rendered & \\
\hline 2010 & $51(30.7 \%)$ \\
\hline 2011 & $31(18.7 \%)$ \\
\hline 2012 & $23(13.9 \%)$ \\
\hline 2013 & $27(16.2 \%)$ \\
\hline 2014 & $10(6 \%)$ \\
\hline 2015 & $22(13.3 \%)$ \\
\hline Not available or confidential & $2(1.2 \%)$ \\
\hline Jury verdict & \\
\hline Defendant & $94(56.6 \%)$ \\
\hline Plaintiff & $40(24.1 \%)$ \\
\hline Settlement & $30(18.1 \%)$ \\
\hline Mixed & $1(0.6 \%)$ \\
\hline Other & $1(0.6 \%)$ \\
\hline Mean payouts; (range) & $\$ 2,266,745.503 ;(\$ 20,000.00-\$ 126,642,039.00)$ \\
\hline Mean plaintiff verdict payout (cases, range) & $\$ 7,213,287.82(39, \$ 325,000-\$ 126,642,039)$ \\
\hline Mean settlement verdict payout (cases, range) & $\$ 2,648,881.44(27, \$ 100,000-\$ 17,000,000)$ \\
\hline Mixed verdict payout (one case) & $\$ 551,500$ \\
\hline
\end{tabular}

TABLE 1: Malpractice litigation related to cardiology 2010-2015 


\section{Cureus}

\begin{tabular}{|l|l|}
\hline Reason for Litigation & Total Cases: 166 \\
\hline Failure to treat & $129(77.7 \%)$ \\
\hline Failure to diagnose & $115(69.3 \%)$ \\
\hline Failure to refer/order diagnostic tests & $107(64.5 \%)$ \\
\hline Other & $43(26 \%)$ \\
\hline Procedural error & $32(19.2 \%)$ \\
\hline Severe hospitalization & $7(4.2 \%)$ \\
\hline Unnecessary surgery & $4(2.4 \%)$ \\
\hline Lack of informed consent & $2(1.2 \%)$ \\
\hline Death & $118(71.1 \%)$ \\
\hline One error & $7(4.21 \%)$ \\
\hline Two errors & $30(18.1 \%)$ \\
\hline Three errors & $42(25.3 \%)$ \\
\hline Four errors & $72(43.4 \%)$ \\
\hline
\end{tabular}

TABLE 2: Reasons for litigation 


\section{Cureus}

\begin{tabular}{|c|c|}
\hline \multicolumn{2}{|c|}{ Geographic Distribution } \\
\hline Florida & $30(18.1 \%)$ \\
\hline New York & $19(11.5 \%)$ \\
\hline Califormia & $18(10.8 \%)$ \\
\hline Massachusetts & $18(10.8 \%)$ \\
\hline Pennsylvania & $14(8.4 \%)$ \\
\hline Illinois & $11(6.6 \%)$ \\
\hline Texas & $7(4.2 \%)$ \\
\hline Connecticut & $6(3.6 \%)$ \\
\hline Michigan & $6(3.6 \%)$ \\
\hline New Jersey & $5(3 \%)$ \\
\hline Ohio & $5(3 \%)$ \\
\hline Washington & $5(3 \%)$ \\
\hline Alabama & $4(2.4 \%)$ \\
\hline Missouri & $4(2.4 \%)$ \\
\hline Delaware & $2(1.2 \%)$ \\
\hline Indiana & $2(1.2 \%)$ \\
\hline New Hampshire & $2(1.2 \%)$ \\
\hline Oklahoma & $2(1.2 \%)$ \\
\hline Arizona & $1(0.6 \%)$ \\
\hline Kansas & $1(0.6 \%)$ \\
\hline Louisiana & $1(0.6 \%)$ \\
\hline Minnesota & $1(0.6 \%)$ \\
\hline Montana & $1(0.6 \%)$ \\
\hline Virginia & $1(0.6 \%)$ \\
\hline
\end{tabular}

TABLE 3: Geographic distribution of malpractice cases

The most common reasons for litigation were failure to treat $(129 ; 77.7 \%)$, death $(118 ; 71.1 \%)$, failure to diagnose $(115 ; 69.3 \%)$, and failure to refer/order diagnostic tests $(107 ; 64.5 \%)$. Among cases involving failure to diagnose as a reason for litigation, the most commonly missed diagnosis was "myocardial infarction", which occurred in 32 cases (19.3\%) (Table 4). Other frequently missed diagnoses were coronary artery disease, aortic dissection, pulmonary embolism, congestive heart failure, and stroke. Missed referrals included surgical and cardiology referrals, whereas missed diagnostic tests included cardiac catheterizations, electrocardiograms, and cardiac biomarkers. The lack of informed consent category under reasons for litigation was excluded from analysis as only two cases involved informed consent, both of which resulted in defendant verdicts. 


\section{Cureus}

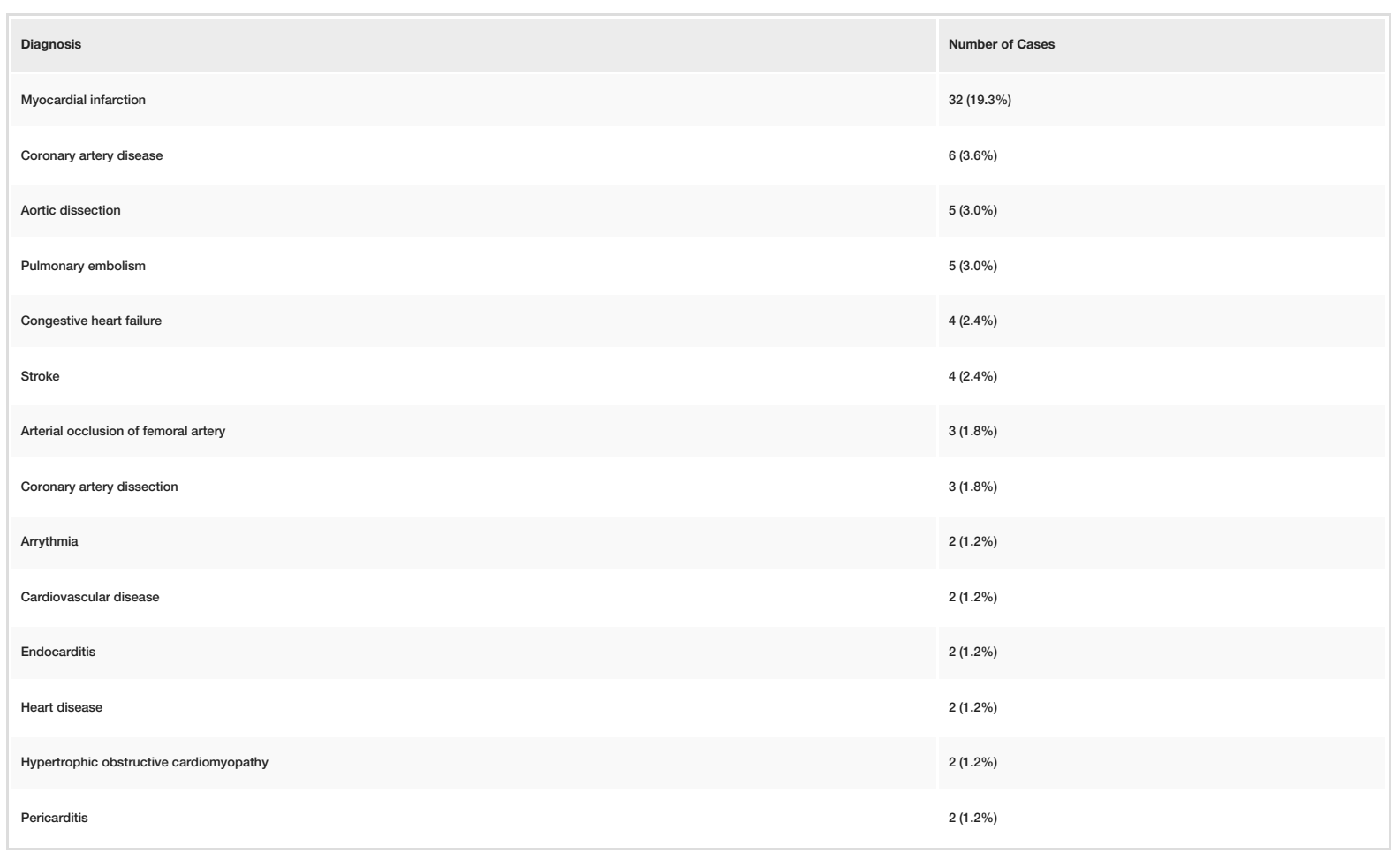

TABLE 4: Most commonly missed diagnoses in cases involving "failure to diagnose" as reason for litigation

The number of defendants per case spanned from one to 10 , with the majority involving either one (58, $34.9 \%$ ) or two defendants $(51,30.7 \%)$. About two thirds of cases involved a cardiologist as a defendant (109; $65.6 \%)$ and a similar proportion involved a hospital or medical group (107, 64.9\%).

Verdicts were in favor of the defendant in 94 cases (56.6\%). Plaintiff verdicts and settlements were reached in $24.1 \%$ and $18.1 \%$ of cases, respectively. Two cases $(1.2 \%)$ had mixed or uncategorized outcomes. The average payout overall was $\$ 2,266,745.50$ with a range of $\$ 20,000.00-\$ 126,642,039.00$.

Outcomes from regression analysis are presented in Table 5 and indicate that failure to diagnose had significantly higher odds of plaintiff verdict compared to defendant verdict (OR $7.60(1.14,50.87), p=0.04)$. Patient age $\geqslant 65$ years, failure to treat in a timely manner, failure to refer/order diagnostic tests, unnecessary surgery, procedural error, severe hospitalization greater than 30 days, and patient death were not associated with jury or settlement outcomes. 


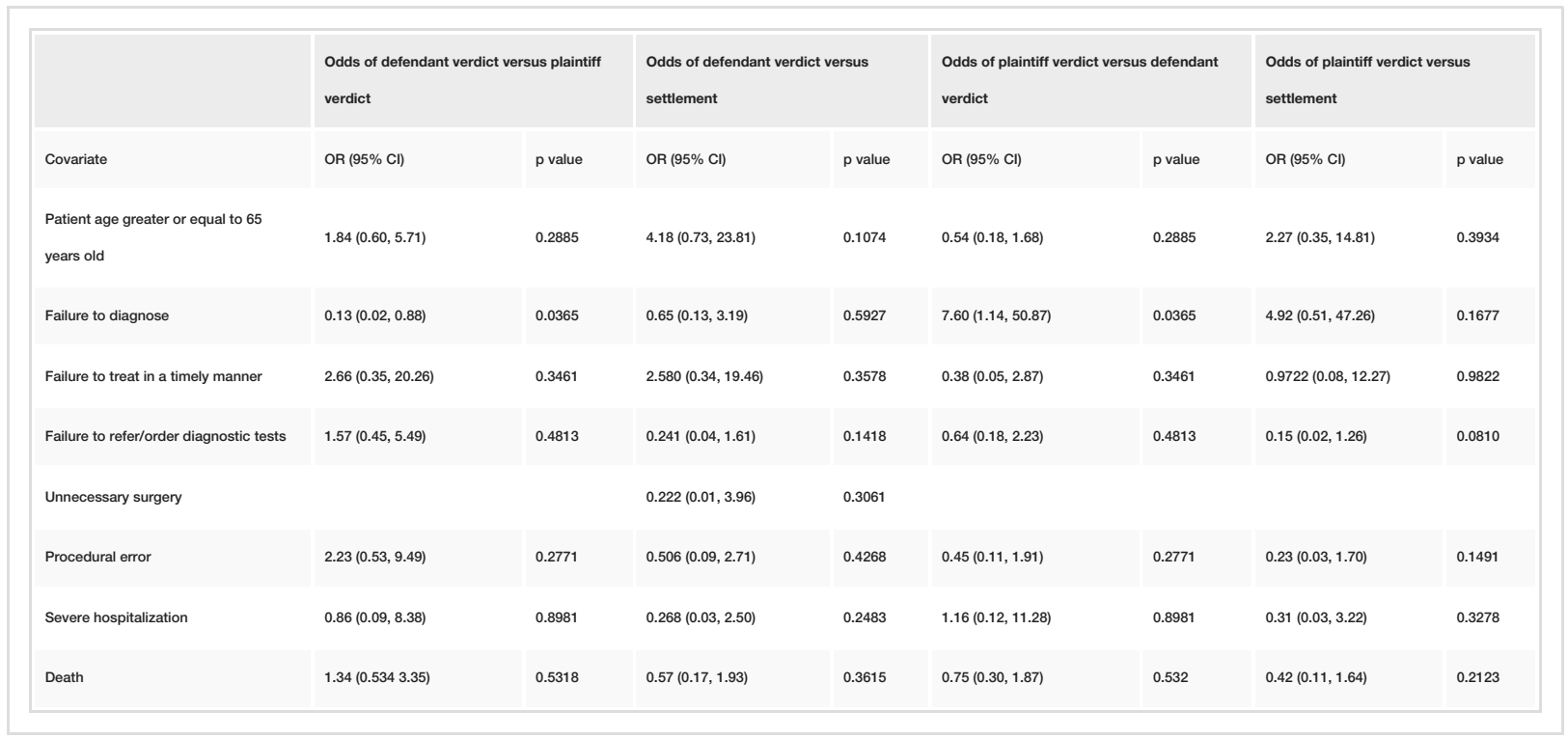

TABLE 5: Logistic regression analysis

\section{Discussion}

The primary goal of this study was to characterize reasons for litigation against cardiologists and to determine if they have remained static in the setting of a changing medicolegal landscape. Our analysis reveals that despite increased use of defensive medicine in recent years, failure to diagnose remained among failure to treat and patient death as the most commonly cited bases for litigation. Among cases that cited failure to diagnose as a reason for litigation, myocardial infarction was the most commonly missed diagnosis.

It is paradoxical that even with documented increases in defensive medicine, physicians are still frequently facing malpractice claims that cite missed diagnoses $[4,15,16]$. This study is unique in that in addition to characterizing cardiology claims, it provides a framework for understanding the predictors of a plaintiff verdict. Therefore, we were able to demonstrate that in addition to the sheer frequency of cases involving failure to diagnose, claims with this basis for litigation cited have a statistically greater odds of a plaintiff verdict. The association of failure to diagnose with a plaintiff verdict is consistent with analyses of litigation in other medical specialties. In a study of otolaryngology malpractice litigation, failure to diagnose was the most common legal allegation, encompassing $51.5 \%$ of cases [17]. In a report on neurosurgery malpractice, failure to diagnose was listed as the third most common reason for litigation preceded only by procedural error and failure to treat [18]. It is critical that future research investigates the systematic reasons as to why diagnoses are missed.

Our study is not the first to ascertain that missed diagnoses of myocardial infarction are at the crux of much of cardiology malpractice litigation [19]. A 2017 retrospective analysis of malpractice claims involving myocardial infarction found that misdiagnosis was the most common claim. The analysis also found that delayed diagnosis resulted in a plaintiff verdict if the physician either failed to work up a patient with coronary artery disease risk factors presenting with the cardinal symptom of chest pain or ischemic heart disease or if the physician failed to perform indicated treatment in a timely manner to avoid disease progression [20]. Of note, cited bases for litigation are obtained from legal proceedings, and the semantics used in law may differ from those in medicine. In the setting of an acute myocardial event, missed diagnosis, misdiagnosis, and delayed diagnosis often have similar morbidity and patient outcomes. We, therefore, argue that the finding of delayed diagnosis resulting in a plaintiff verdict corroborates our finding of failure to diagnose resulting in a plaintiff verdict.

Defensive medicine is often critiqued for subjecting patients to a greater number of tests and increasing healthcare costs, and current literature remains inconclusive as to whether defensive medicine has patient merit. In an analysis of patients with acute myocardial infarctions admitted to California hospitals, patients in the highest quintile of hospital spending had lower inpatient mortality rates compared to those in the lowest quintile [21]. Increased hospital spending correlated with a greater number of diagnostic tests ordered. Another study amongst internists found that the internists in the highest fifth of patient riskadjusted resource use were approximately half as likely to face future malpractice claims when compared to internists in the lowest fifth [22]. Increased use of resources was associated with both a decrease in litigation and improved patient health outcomes. Contrary to the findings of these two studies, a recent study of defensive medicine in the military, a setting in which physicians are immune from medical malpractice 
lawsuits, indicated that liability immunity reduced inpatient spending by $5 \%$, with no negative ramifications on patient outcomes [23]. Frakes et al. argued that because defensive medicine is conducted unsystematically and without proper clinical suspicion, it does not result in improvements in patient care [23]. Furthermore, eliminating the impetus for defensive medicine via medical malpractice immunity did not decrease the quality of patient care $[23,24]$.

We also identified that cardiologists were not defendants in a large portion of cases. The high percentage of non-cardiologists implicated in cardiology medical malpractice claims highlights the role of other specialties and healthcare professionals in recognizing and managing acute cardiac events. Due to the acuity of myocardial infarctions, patients may not necessarily present to a cardiologist, often presenting to a primary care physician or the emergency department. It can be argued that in this regard, ordering an electrocardiogram may be an appropriate constitution of defensive medicine, as the consequences of a missed diagnosis of myocardial infarction are detrimental, and this inexpensive test likely does not constitute a significant portion of defensive medicine's contribution to rising healthcare costs. However, the failure of this method in detecting myocardial infarctions lies in the interpretations of the electrocardiograms. Studies have found that despite the introduction of computerized interpretations, medical students and physicians of a variety of specialties may not be adequately trained to read electrocardiograms, and this can lead to adverse outcomes [25].

Increased education in cultural competencies and atypical presentations of myocardial infarction may also play a pivotal role in decreasing missed diagnoses of myocardial infarction. Women less than the age of 55 and non-white individuals presenting to the emergency room with symptoms of acute cardiac ischemia are significantly less likely to be hospitalized than men and white counterparts, respectively [26]. Inherit biases may also play a role in missing diagnoses. Diagnostic errors have previously been categorized as either nofault errors, system-related errors, cognitive-related errors, or a mixture of all three [27]. Cognitive related errors are, to some degree, a result of inherent biases and have been shown to contribute to physicians' assessments of patients' presenting symptoms. Therefore, missed diagnoses may be reduced by training physicians to be more cognizant of subconscious biases during patient assessments.

There are several limitations to this study. Although the WestlawNext ${ }^{\mathrm{TM}}$ search engine includes large numbers of cases from federal and state courts, case submission is not mandatory, and the database does not contain out of court malpractice settlements. As a result, our sample size was limited. For example, the initial review of the 166 cases that met inclusion criteria revealed too few cases involving unnecessary surgery and failure of informed consent as reasons for litigation to calculate odds ratios for verdict outcomes. It is possible that such allegations have limited incidence in cardiology. For example, while there are certainly variations in the procurement of informed consent, physicians across all specialties are aware of the legal consequences of performing procedures without consent, more so than ever before [28]. Additionally, defendant physician professional and demographic information such as years of experience, age, history of previous litigation, and medical education were not consistently available for analysis. Decreased age, previous litigation, and lower quality medical education based on national rankings of institutions are all independently associated with increased odds of being involved in malpractice suits [29]; we were unable to investigate the associations of these factors in our analysis.

\section{Conclusions}

This analysis of cardiology malpractice claims over a six-year period confirmed our hypothesis that failure to diagnose is a common reason for litigation and a statistically significant predictor of a plaintiff verdict; this is despite documented increases in defensive medicine over the past decade. While this study cannot isolate the impact of defensive medicine on missed cardiovascular diagnoses, it is imperative to recognize that defensive medicine alone is evidently insufficient to protect both physicians and patients. As myocardial infarction was the most frequently missed diagnosis, further research is warranted to investigate downfalls in diagnosis with a focus on electrocardiogram interpretation and cultural competency. Attention to this diagnosis has the potential to improve patient outcomes, decrease the burden of medical malpractice claims, and optimize the allocation of healthcare dollars.

\section{Additional Information}

\section{Disclosures}

Human subjects: All authors have confirmed that this study did not involve human participants or tissue. Animal subjects: All authors have confirmed that this study did not involve animal subjects or tissue. Conflicts of interest: In compliance with the ICMJE uniform disclosure form, all authors declare the following: Payment/services info: All authors have declared that no financial support was received from any organization for the submitted work. Financial relationships: All authors have declared that they have no financial relationships at present or within the previous three years with any organizations that might have an interest in the submitted work. Other relationships: All authors have declared that there are no other relationships or activities that could appear to have influenced the submitted work.

\section{References}


1. Carrier ER, Reschovsky JD, Katz DA, Mello MM: High physician concern about malpractice risk predicts more aggressive diagnostic testing in office-based practice. Health Aff. 2013, 32:1383-1391.

10.1377/hlthaff.2013.0233

2. Studdert DM, Mello MM, Sage WM, DesRoches CM, Peugh J, Zapert K, Brennan TA: Defensive medicine among high-risk specialist physicians in a volatile malpractice environment. JAMA. 2005, 293:2609-2617. 10.1001/jama.293.21.2609

3. Katz DA, Williams GC, Brown RL, Aufderheide TP, Bogner M, Rahko PS, Selker HP: Emergency physicians' fear of malpractice in evaluating patients with possible acute cardiac ischemia. Ann Emerg Med. 2005, 46:525-533. 10.1016/j.annemergmed.2005.04.016

4. Mello MM, Chandra A, Gawande AA, Studdert DM: National costs of the medical liability system. Health Aff. 2010, 29:1569-1577. 10.1377/hlthaff.2009.0807

5. Mangalmurti S, Seabury SA, Chandra A, Lakdawalla D, Oetgen WJ, Jena AB: Medical professional liability risk among US cardiologists. Am Heart J. 2014, 167:690-696. 10.1016/j.ahj.2014.02.007

6. Oetgen WJ, Parikh PD, Cacchione JG, et al.: Characteristics of medical professional liability claims in patients with cardiovascular diseases. Am J Cardiol. 2010, 105:745-752. 10.1016/j.amjcard.2009.10.072

7. Levinson W: Physician-patient communication: a key to malpractice prevention . JAMA. 1994, 272:16191620. 10.1001/jama.1994.03520200075039

8. Roter D: The patient-physician relationship and its implications for malpractice litigation . J Health Care L \& Pol'y. 2006, 9:304-314.

9. Rynecki ND, Coban D, Gantz O, et al.: Medical malpractice in orthopedic surgery: a Westlaw-based demographic analysis. Orthopedics. 2018, 41:615-620. 10.3928/01477447-20180621-06

10. Peoples LF: Testing the limits of WestlawNext. Legal Ref Serv Q. 2012, 31:125-149. 10.1080/0270319X.2012.682928

11. Colaco M, Heavner M, Sunaryo P, Terlecki R: Malpractice litigation and testicular torsion: a legal database review. J Emerg Med. 2015, 49:849-854. 10.1016/j.jemermed.2015.06.052

12. Stolz L, O'Brien KM, Miller ML, Winters-Brown ND, Blaivas M, Adhikari S: A review of lawsuits related to point-of-care emergency ultrasound applications. West J Emerg Med. 2015, 16:1-4.

10.5811/westjem.2014.11.23592

13. Gordhan CG, Anandalwar SP, Son J, Ninan GK, Chokshi RJ: Malpractice in colorectal surgery: a review of 122 medicolegal cases. J Surg Res. 2015, 199:351-356. 10.1016/j.jss.2015.05.032

14. Blake DM, Svider PF, Carniol ET, Mauro AC, Eloy JA, Jyung RW: Malpractice in otology. Otolaryngol Head Neck Surg. 2013, 149:554-561. 10.1177/0194599813498696

15. Baltic S: Tort reform: while some states have taken action to cap damages, fear of litigation still drives defensive medicine. Med Econ. 2013, 90:20-22, 24-26.

16. Chen J, Majercik S, Bledsoe J, et al.: The prevalence and impact of defensive medicine in the radiographic workup of the trauma patient: a pilot study. Am J Surg. 2015, 210:462-467. 10.1016/j.amjsurg.2015.03.016

17. Hong SS, Yheulon CG, Wirtz ED, Sniezek JC: Otolaryngology and medical malpractice: a review of the past decade, 2001-2011. Laryngoscope. 2014, 124:896-901. 10.1002/lary.24377

18. Thomas R, Gupta R, Griessenauer CJ, et al.: Medical malpractice in neurosurgery: a comprehensive analysis . World Neurosurg. 2017, 110:552-559. 10.1016/j.wneu.2017.11.051

19. Abbott R, Cohen M: Medico-legal issues in cardiology. Cardiol Rev. 2013, 21:222-228. 10.1097/CRD.0b013e31828af110

20. Wu K-H, Yen Y-L, Wu C-H, Hwang C-Y, Cheng S-Y: Learning from an analysis of closed malpractice litigation involving myocardial infarction. J Forensic Leg Med. 2017, 48:41-45. 10.1016/j.jflm.2017.04.003

21. Romley JA, Jena AB, Goldman DP: Hospital spending and inpatient mortality: evidence from California: an observational study. Ann Intern Med. 2011, 154:160-167. 10.7326/0003-4819-154-3-201102010-00005

22. Jena AB, Schoemaker L, Bhattacharya J, Seabury SA: Physician spending and subsequent risk of malpractice claims: observational study. BMJ. 2015, 351:h5516. 10.1136/bmj.h5516

23. Frakes MD, Gruber J: Defensive medicine: evidence from military immunity. NBER Work Pap Ser. 2018, 24846:1-50. Accessed: 1/24/2019: 10.3386/w24846

24. Sanger-Katz M: A fear of lawsuits really does seem to result in extra medical tests . New York Times. 2018, Accessed: 12/4/2018: https://www.nytimes.com/2018/07/23/upshot/malpractice-lawsuits-medicalcosts.html.

25. Fent G, Gosai J, Purva M: Teaching the interpretation of electrocardiograms: which method is best? . J Electrocardiol. 2015, 48:190-193. 10.1016/j.jelectrocard.2014.12.014

26. Pope JH, Aufderheide TP, Ruthazer R, et al.: Missed diagnoses of acute cardiac ischemia in the emergency department. N Engl J Med. 2000, 342:1163-1170. 10.1056/NEJM200004203421603

27. Graber ML, Franklin N, Gordon R: Diagnostic error in internal medicine. Arch Intern Med. 2005, 165:14931499. 10.1001/archinte.165.13.1493

28. Rao KS: Informed consent: an ethical obligation or legal compulsion? J Cutan Aesthet Surg. 2008, 1:33-35. 10.4103/0974-2077.41159

29. Weycker DA, Jensen GA: Medical malpractice among physicians: who will be sued and who will pay? . Health Care Manag Sci. 2000, 3:269-277. 10.1023/A:1019014028914 